\title{
News from Universities - Nouvelles universitaires
}

\section{Universitätsnachrichten}

Germany - Allemagne - Deutschland

Ber\%o/Humboldt-Universität: Prof. Dr. med. A.Waldeyer wurde als Nachfolger des verstorbenen Prof. Dr. med. et phil. H. Stíeve auf den Lehrstuhl für Anatomie berufen.

Prof. Dr. med. Walther Kirsche wurde zum ordentlichen Professor für Anatomie ernannt.

Gíeßen: Prof. Dr. phil. W. J. Schmidt, der emeritierte Ordinarius für Zoologie wurde von der Medizinischen Fakultät Bonn in Anerkennung seiner grundlegenden Arbeiten über den Feinbau der Zahngewebe zum Dr. med. dent. h. c. promoviert.

München: Professor Dr. med. Siegfried Mollier, der emeritierte langjährige Professor für Anatomie an der Universität München, ist am 18. August 1954 im 89. Lebensjahr verstorben. Tubingen: Dr. med. Gundo Boehm, in Basel, Mitherausgeber unserer Zeitschrift, ist zum Honorarprofessor an der Universität Tubingen ernannt worden.

Austria - Autriche - österreich

Wien: Am 10. November 1954 verstarb in seinem 94. Lebensjahr der emeritierte Vorstand der II. Anatomischen Lehrkanzel an der Universität Wien, Prof. Dr. med., Dr. phil. h. c. Ferdinand Hochstetter, Ehren-vorsitzender der Anatomischen Gesellschaft. Dr. med. Leopold Stockinger hat sich für Histologie und Embryologie habilitat. 